\title{
dspace.vutbr.cz
}

\section{Third-Order Reconnection-less Electronically Reconfigurable Multifunctional Filter}

\author{
LANGHAMMER, L.; ŠOTNER, R.
}

Proceedings of the 2020 IEEE International Symposium on Circuits and Systems (ISCAS)

elSBN: 978-1-7281-3320-1

DOl: https://doi.org/10.1109/ISCAS45731.2020.9180562

Accepted manuscript

C2020 IEEE. Personal use of this material is permitted. Permission from IEEE must be obtained for all other uses, in any current or future media, including reprinting/republishing this material for advertising or promotional purposes, creating new collective works, for resale or redistribution to servers or lists, or reuse of any copyrighted component of this work in other works. LANGHAMMER, L.; ŠOTNER, R. "Third-Order Reconnection-less Electronically Reconfigurable Multifunctional Filter", Proceedings of the 2020 IEEE International Symposium on Circuits and Systems (ISCAS), 2020. DOI: 10.1109/ISCAS45731.2020.9180562. Final version is available at https://ieeexplore.ieee.org/document/9180562 


\section{Third-Order Reconnection-less Electronically Reconfigurable Multifunctional Filter}

\author{
Lukas Langhammer \\ Faculty of Electrical Engineering and Communication \\ Brno University of Technology \\ Technicka 12, 61600 Brno, Czech Republic \\ langhammer@feec.vutbr.cz
}

\author{
Roman Sotner \\ Faculty of Electrical Engineering and Communication \\ Brno University of Technology \\ Technicka 12, 61600 Brno, Czech Republic \\ sotner@feec.vutbr.cz
}

\begin{abstract}
This paper introduces a third-order reconnection-less electronically reconfigurable filter constructed of operational transconductance amplifiers (OTAs) and a current amplifier with individual gain control of its outputs. All capacitors in the filter structure are grounded. The filter offers thirteen transfer functions based on the configuration of current gains without a necessity of any manual reconnection or modification. The design is verified by PSpice simulations alongside with experimental measurements using available active elements.
\end{abstract}

Keywords-electronic controllability, higher-order filter, multifunctional filter, reconnection-less filter

\section{INTRODUCTION}

In recent years, it is possible to come across the research dealing with a topic of reconnection-less electronically reconfigurable filters [1-6] due to their ability to change the resulting output response without any manual switching of the input and/or output nodes of the filter, or structure modification. Other possible advantage of mentioned structures is the fine tuning (gain level adjustment) of stopband/pass-band area if the function does not meet our demands. The idea of reconnection-less filters is based on usage of active elements offering the electronic controllability of their parameters, usually the transconductance $g_{\mathrm{m}}$ in case of an operational transconductance amplifier (OTA), or voltage or current gain $A / B$ assuming usage of voltage/current amplifiers. These controllable parameters (typically controlled by DC control voltage/current) can cancel chosen terms of the numerator of the transfer function of the proposed filter resulting in different output responses based on the parameter(s) setting. This approach can be beneficial in case of on-chip implementation when we do not possess the possibility to modify the structure or switch between the nodes of the filter, for instance.
When it comes to the filters of higher-order (higher than $2^{\text {nd }}$-order) [7-13], these filtering structures are usually designed to operate as one-purpose filters offering only one specific function [7-10], or if they offer more than one function [11-13], they are designed in similar manner as the $2^{\text {nd }}$-order filters (not offering the ability of the electronic reconnection) requiring switching between the specific nodes of the circuit topology. To the best of author's knowledge, there was no report of the reconnection-less electronically reconfigurable filter of higher order and this area is worth the investigation. A possible theoretical approach to this issue, specifically for filters working in the current mode, has been provided in [14]. The first suggested approach lies in the distribution of the input current into individual structure nodes by means of current gains. These current gains are controlled electronically and they can be set depending on the output response we want to obtain. The other presumed method is consisting of the summation of responses taken from individual structure nodes again based on the setting of specific current gains in order to obtain a desired function. The first mentioned procedure from [14] was used in the proposal. Tab. I gives a comparison of above-mentioned higher-order filters and the reconnection-less $3^{\text {rd }}$-order filter proposed in this paper. Table II, on the other hand, compares previously introduced reconnection-less filter (all of the second-order) with the proposed filter.

The filter introduced in this paper is a $3^{\text {rd }}$-order filter based on Inverse Follow-the-Leader feedback (IFLF) topology offering 13 transfer functions (low-pass (LP) function of the $3^{\text {rd }}, 2^{\text {nd }}$ and $1^{\text {st }}$ order, high-pass (HP) function of the $3^{\text {rd }}$ and $2^{\text {nd }}$ order, band-pass (BP) function of the $2^{\text {nd }}$ order, asymmetrical BP 20/40 dB per decade and 40/20 dB per decade, two band-stop (BS) functions, all-pass (AP) function of the $2^{\text {nd }}$ and $1^{\text {st }}$ order and inverting direct transfer (IDT)) all obtainable by electronic means.

TABLE I. COMPARISON OF RELEVANT HIGHER ORDER FILTERS

\begin{tabular}{|c|c|c|c|c|c|c|c|c|}
\hline Reference & {$[7]$} & {$[8]$} & [9] & {$[10]$} & [11] & [12] & [13] & Fig. 3 \\
\hline $\begin{array}{l}\text { Number of active/passive } \\
\text { elements }\end{array}$ & $10 / 20$ & $2 / 8$ & $3 / 3$ & $4 / 8$ & $5 / 4$ & $1 / 8$ & $3 / 3$ & $4 / 3$ \\
\hline Order of the filter & $5^{\text {th }}$ & $3^{\text {rd }}$ & $3^{\text {rd }}$ & $4^{\text {th }}$ & $4^{\text {th }}$ & $4^{\text {th }}$ & $3^{\text {rd }}$ & $3^{\text {rd }}$ \\
\hline All capacitors grounded & Yes & No & Yes & No & Yes & No & Yes & Yes \\
\hline $\begin{array}{l}\text { Number of available } \\
\text { functions }\end{array}$ & 1 (LP) & $1(\mathrm{LP})$ & $1(\mathrm{BP})$ & $1(\mathrm{LP})$ & 2 (LP, HP) & $2(\mathrm{BP}, \mathrm{AP})$ & $2(\mathrm{LP}, \mathrm{BP})$ & 13 \\
\hline Simulations/Meaurement & Yes/No & Yes/No & Yes/No & Yes/No & Yes/No & Yes/No & Yes/No & Yes/Yes \\
\hline
\end{tabular}

For the research, infrastructure of the SIX Center was used. 
TABLE II. COMPARISON OF PREVIOUSLY REPORTED RECONNECTIONLESS RECONFIGURABLE FILTERS

\begin{tabular}{|c|c|c|c|c|}
\hline & & & & \\
\hline & & 0 & & \\
\hline$[1]$ & $4 / 4$ & Yes & 7 & Yes/No \\
\hline$[2]$ & $4 / 2(3)$ & No & 7 & Yes/No \\
\hline$[3]$ & $4 / 2$ & No & 6 & Yes/No \\
\hline$[4]$ & $2 / 3$ & Yes & 5 & Yes/Yes \\
\hline$[5]$ & $5 / 2$ & No & 9 & Yes/No \\
\hline$[6]$ & $4 / 2$ & No & 6 & Yes/Yes \\
\hline Fig. 3 & $4 / 3$ & Yes & 13 & Yes/Yes \\
\hline
\end{tabular}

\section{CIRCUIT DESIGN}

The proposed filter has been designed directly based on IFLF topology. Subsequently, the appropriate output polarity combination, in order to ensure the filter stability, has been achieved using Symbolic Network Analysis Program (SNAP) software [15]. The main building block used for the design is an operational transconductance amplifier [16] following relation $I_{\text {out } \pm}= \pm g_{\mathrm{m}} \cdot\left(V_{\mathrm{in}+}-V_{\mathrm{in}-}\right)$, where $g_{\mathrm{m}}$ stands for the transconductance of given element. Its schematic symbol (for the OTA with four outputs) and its implementation employing the universal current conveyor (UCC) [17] are shown in Fig. 1 a), b). The UCC has been implemented in CMOS $0.35 \mu \mathrm{m}$ process. The implemented chip is labeled as UCC-N1B_0520 device. Since each UCCN1B 0520 chip contains one UCC together with a secondgeneration current conveyor with two outputs ( $\mathrm{CCII} \pm$ ), the OTA elements in the filter structure requiring only one output were implemented using the CCII \pm from the chip. This implementation does not directly offer the electronic control of the transconductance nonetheless, commercially available devices with the electronic control of their transconductance usually possess only one output while $\mathrm{OTA}_{3}$ in the proposed structure requires four outputs. To implement the OTA with the electronic control of its transconductance, it would be possible to use LT1228 device [18], for example, in combination with the UCC (where the LT1228 provides the electronic control of the transconductance (by DC control current) and the UCC is used as a current follower to obtain copies of the output current).

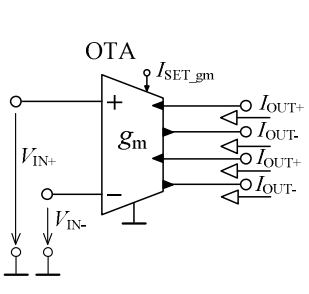

a)

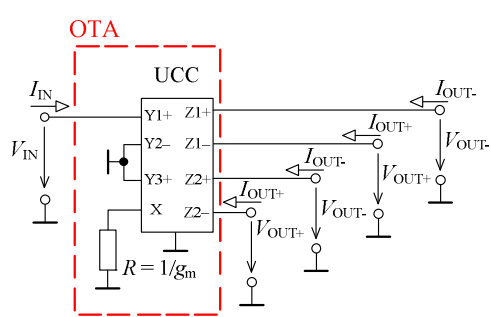

b)
Fig. 1. Operational transconductance amplifier (OTA): a) schematic symbol, b) implementation using the UCC.
To provide the input current distribution, a current amplifier with individual gain control of each output introduced in [19] (in text referred to as individual output gain controlled current amplifier (IOGC-CA)) has been used. The proposed current amplifier from [19] is simplified removing the input part providing the controllable intrinsic resistance because it is not necessary for the particular filter design. Fig. 2 a) depicts a schematic symbol of the IOGC$\mathrm{CA}$ element while Fig. 2 b) introduces the inter structure of this element implemented by one UCC acting as a current follower and four adjustable current amplifiers (ACAs) made by EL2082 devices [20] ( $B$ is controlled by DC control voltage in case of this device) in case of this active element realization. The function of the IOGC-CA is described by relation $I_{\mathrm{OUT}} \pm= \pm B \mathrm{i}\left(\mathrm{IIN}_{\mathrm{IN}}\right)$, where $i=\{0,1,2,3\}$ based on specific output.

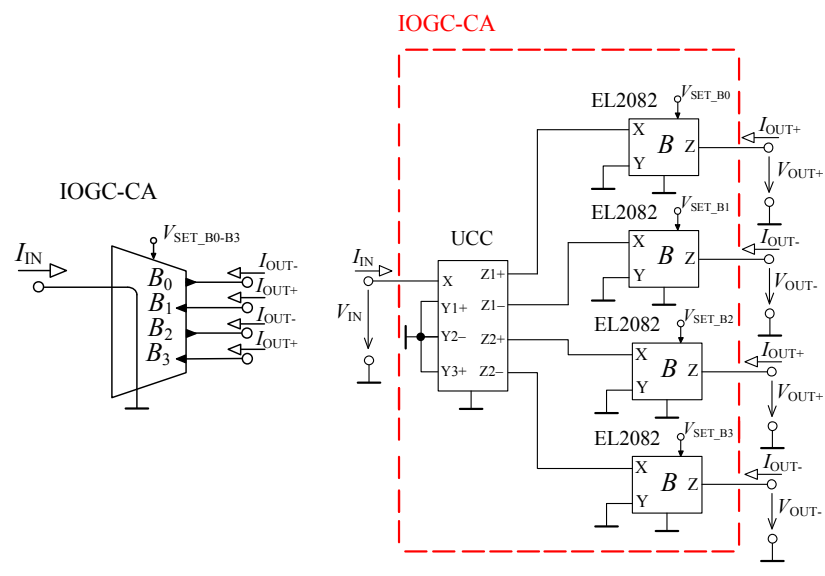

a)

b)

Fig. 2. Independent output gain controlled current amplifier (IOGC-CA): a) schematic symbol, b) implementation by the UCC and EL2082 devices.

The proposed filter, depicted in Fig. 3, comprises three OTA elements (two with one output and one with four outputs), one IOGC-CA element and three capacitors (all grounded). The transfer function is given as $K(\boldsymbol{s})=\boldsymbol{I}_{\mathrm{OUT}} / \boldsymbol{I}_{\mathrm{IN}}=N(\boldsymbol{s}) / D(\boldsymbol{s})$ where:

$$
\begin{aligned}
& N(\boldsymbol{s})=\boldsymbol{s}^{3} B_{3} C_{1} C_{2} C_{3}+ \\
&+ \boldsymbol{s}^{2}\left(B_{3} C_{1} C_{2} g_{m 3}-B_{2} C_{1} C_{2} g_{m 3}\right)+ \\
&+ \boldsymbol{s}\left(B_{3} C_{1} g_{m 2} g_{m 3}-B_{1} C_{1} g_{m 2} g_{m 3}\right)+ \\
& B_{3} g_{m 1} g_{m 2} g_{m 3}-B_{0} g_{m 1} g_{m 2} g_{m 3} \\
& D(\boldsymbol{s})= \boldsymbol{s}^{3} C_{1} C_{2} C_{3}+\boldsymbol{s}^{2} C_{1} C_{2} g_{m 3}+\boldsymbol{s} C_{1} g_{m 2} g_{m 3}+ \\
&+g_{m 1} g_{m 2} g_{m 3}
\end{aligned}
$$

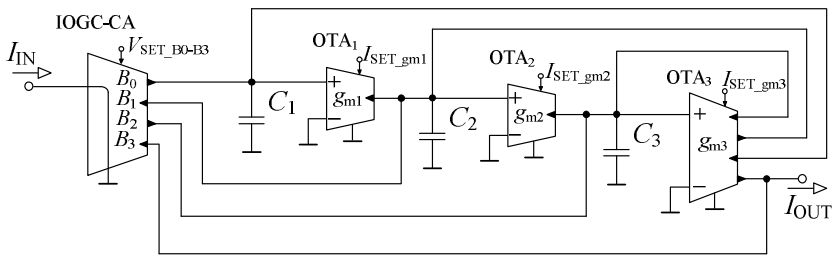

Fig. 3. Proposed $3^{\text {rd }}$-order reconnection-less electronically reconfigurable filter. 
From (1), it can be seen that resulting output response will be depending on setting of current gains $B_{0}$ to $B_{3}$ (controllable by DC control voltages $V_{\text {SET_B0 }}$ to $V_{\text {SET_B3 }}$ in case of used implementation). A list of available functions based on the setting of $V_{\text {SET_B }}$ to $V_{\text {SET_B3 }}$ is given in Tab III. Since it is common that some functions obtained from higher-order filters have their pass-band shifted in gain into positive values (not having a unity gain of $0 \mathrm{~dB}$ ), the values stated in Tab III are already adjusted in order to offer functions with their pass-band being equal to $0 \mathrm{~dB}$ since the gain level of each function can be easily controlled. It could be also possible to obtain other functions if the current gains were settable in both polarities, or some current gains were set higher than one.

TABLE III. AVAILABLE TRANSFER FUNCTIONS IN ACCORDANCE WITH THE CONTROL VOLTAGES CONFIGURATION

\begin{tabular}{|c|c|c|c|c|}
\hline $\mathbf{V}_{\text {SET_B3 }}$ & $\mathbf{V}_{\text {SET_B2 }}$ & $\mathbf{V}_{\text {SET_B1 }}$ & $\mathbf{V}_{\text {SET_B0 }}$ & function \\
\hline $0 \mathrm{~V}$ & $0 \mathrm{~V}$ & $0 \mathrm{~V}$ & $1 \mathrm{~V}$ & LP $\left(3^{\text {rd }}\right.$-order $)$ \\
\hline $0 \mathrm{~V}$ & $0 \mathrm{~V}$ & $0.75 \mathrm{~V}$ & $0 \mathrm{~V}$ & $\mathrm{BP}(20 / 40 \mathrm{~dB} / \mathrm{dec})$ \\
\hline $0 \mathrm{~V}$ & $0 \mathrm{~V}$ & $0.25 \mathrm{~V}$ & $1 \mathrm{~V}$ & LP $\left(2^{\text {nd }}-\right.$ order $)$ \\
\hline $0 \mathrm{~V}$ & $0.75 \mathrm{~V}$ & $0 \mathrm{~V}$ & $0 \mathrm{~V}$ & $\mathrm{BP}(40 / 20 \mathrm{~dB} / \mathrm{dec})$ \\
\hline $0 \mathrm{~V}$ & $0.5 \mathrm{~V}$ & $0.5 \mathrm{~V}$ & $0 \mathrm{~V}$ & $\mathrm{BP}\left(2^{\text {nd }}-\right.$ order $)$ \\
\hline $0 \mathrm{~V}$ & $0.5 \mathrm{~V}$ & $0.5 \mathrm{~V}$ & $1 \mathrm{~V}$ & LP ( $1^{\text {st }}$-order $)$ \\
\hline $1 \mathrm{~V}$ & $0 \mathrm{~V}$ & $0 \mathrm{~V}$ & $0 \mathrm{~V}$ & IDT \\
\hline $1 \mathrm{~V}$ & $0 \mathrm{~V}$ & $0.8 \mathrm{~V}$ & $0 \mathrm{~V}$ & BS (2 $2^{\text {nd }}-$ order $)$ \\
\hline $1 \mathrm{~V}$ & $0 \mathrm{~V}$ & $1 \mathrm{~V}$ & $1 \mathrm{~V}$ & HP ( $2^{\text {nd }}$-order $)$ \\
\hline $1 \mathrm{~V}$ & $0.8 \mathrm{~V}$ & $0 \mathrm{~V}$ & $0 \mathrm{~V}$ & BS (2 ${ }^{\text {nd }}$-order $)$ \\
\hline $1 \mathrm{~V}$ & $1 \mathrm{~V}$ & $1 \mathrm{~V}$ & $0 \mathrm{~V}$ & $\mathrm{AP}\left(2^{\text {nd }}\right.$-order $)$ \\
\hline $1 \mathrm{~V}$ & $1 \mathrm{~V}$ & $1 \mathrm{~V}$ & $1 \mathrm{~V}$ & HP $\left(3^{\text {rd }}\right.$-order $)$ \\
\hline $1 \mathrm{~V}$ & $1 \mathrm{~V}$ & $1 \mathrm{~V}$ & $2 \mathrm{~V}$ & $\mathrm{AP}\left(1^{\text {st }}\right.$-order $)$ \\
\hline
\end{tabular}

\section{NuMERICAL DESIGN AND VERIFICATION}

The first step of the numerical design was using the NAF tool [21] designed to calculate individual coefficients of the transfer function in dependence on the desired order of the filter and used approximation. The following parameters (for Butterworth approximation) were used: the pole frequency $f_{0}=47 \mathrm{kHz}$, transfer in pass-band $K_{\mathrm{P}}=-3 \mathrm{~dB}$, the stop-band frequency $f_{\mathrm{s}}=470 \mathrm{kHz}$, transfer in stop-band $K_{\mathrm{S}}=-60 \mathrm{~dB}$. The calculated denominator coefficients for this configuration are as follows:

$$
\begin{gathered}
b_{3}=1, \\
b_{2}=5.995 \cdot 10^{5}, \\
b_{1}=1.797 \cdot 10^{11}, \\
b_{0}=2.694 \cdot 10^{16} .
\end{gathered}
$$

Applying the coefficients from (3) into (2) while selecting the values of capacitors to be $C_{1}=C_{2}=C_{3}=1 \mathrm{nF}$ results in values of transconductances $g_{\mathrm{m} 3}=b_{2} C_{3}=150 \mu \mathrm{S}$, $g_{\mathrm{m} 2}=\left(b_{1} C_{2} C_{3}\right) / g_{\mathrm{m} 3}=300 \mu \mathrm{S}$ and $g_{\mathrm{m} 1}=\left(b_{0} C_{1} C_{2} C_{3}\right) /\left(g_{\mathrm{m} 2} g_{\mathrm{m} 3}\right)$ $=600 \mu \mathrm{S}$.

The simulation results were carried out in PSpice software using CMOS models in $0.18 \mu \mathrm{m}$ TSMC technology. Used transistor-level models of a current follower, current amplifier and operational transconductance amplifier can be found in [22], [23] and [24], respectively. The supply voltage of all simulation models is $\pm 1 \mathrm{~V}$. The filter has been implemented in form of a printed circuit board (PCB) in order to perform experimental measurements with help of a network analyzer Agilent 4395A and V/I, I/V converters. The convertors were constructed by OPA860 [25] and OPA861 [26] devices. The active elements, in case of the experimental measurements, are implemented as suggested in section II.

The simulation results compared with the experimental measurements of chosen available transfer functions in case of the magnitude and phase characteristics are depicted in Fig. 4 and Fig. 5. Fig. 4 shows output responses of the $3^{\text {rd }}$ order HP, $2^{\text {nd }}$-order $\mathrm{BP}$ and $1^{\text {st }}$-order AP while Fig. 5 displays functions of inverting direct transfer, $2^{\text {nd }}$-order LP and $1^{\text {st }}$-order LP. The differences between the simulation and experimental results as well as the non-idealities of the output responses in both cases are mainly given by the parasitic characteristics of used simulation models, real characteristics of chips used in case of implementation, respectively. It can be seen that responses start to deviate at around $5 \mathrm{MHz}$ due to bandwidth limitations of used active elements. The expected characteristics of the UCC are $R_{\mathrm{iIN}}=2 \Omega, C_{\mathrm{iIN}}=1 \mathrm{pF}, R_{\mathrm{vIN}}=1 \mathrm{M} \Omega, C_{\mathrm{vIN}} 1 \mathrm{pF}$ and $R_{\text {OUT }}=100 \mathrm{k} \Omega, C_{\text {OUT }}=1 \mathrm{pF}$. Characteristics of the EL2082 stated in its datasheet are $R_{\mathrm{iIN}}=95 \Omega, C_{\mathrm{iIN}}=2 \mathrm{pF}$, $R_{\mathrm{vIN}}=1 \mathrm{M} \Omega, C_{\mathrm{vIN}}=2 \mathrm{pF}$ and $R_{\mathrm{OUT}}=500 \mathrm{k} \Omega, C_{\text {OUT }}=5 \mathrm{pF}$. The parasitic capacitance of the PCB is expected to be $30 \mathrm{pF}$. Thus, the effect of parasitic capacitances should be negligible

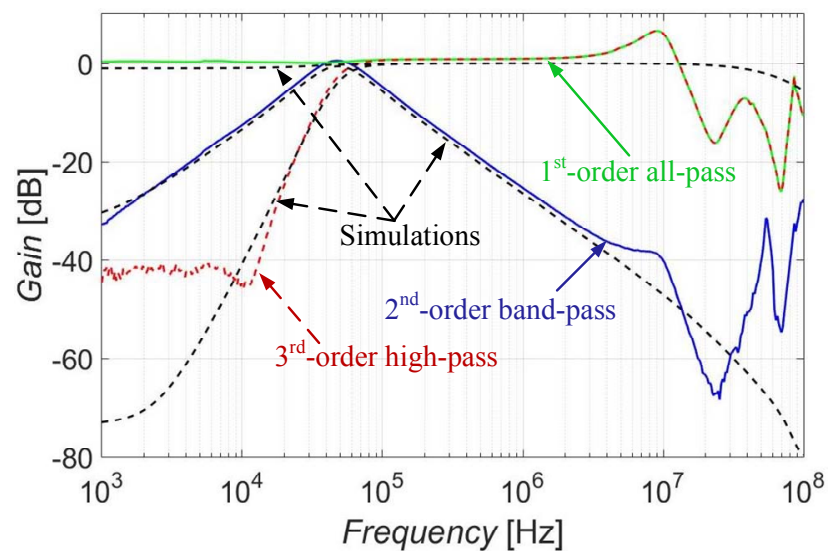

a)

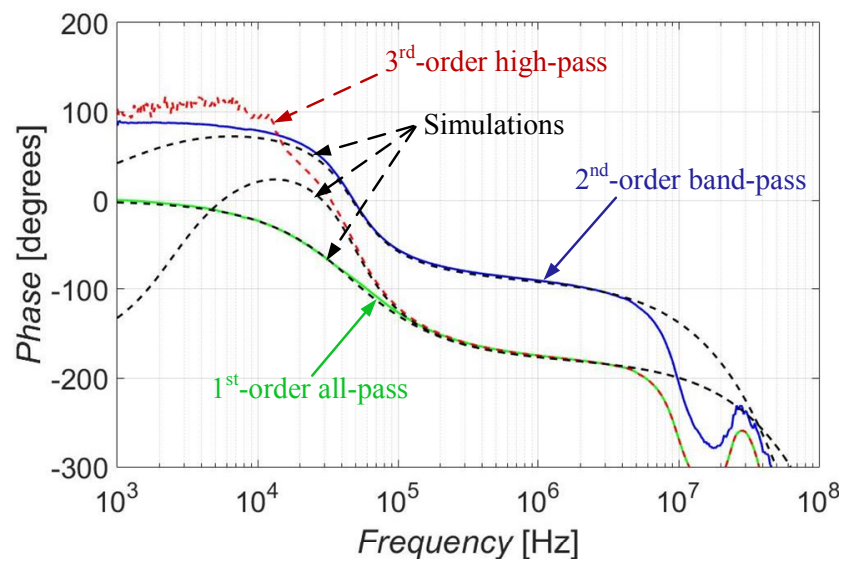

b)

Fig. 4. Transfer functions $3^{\text {rd }}$-order HP, $2^{\text {nd }}$-order BP and $1^{\text {st }}$-order AP: a) magnitude characteristics, b) phase characteristics. 
in comparison to the used value of the working capacitors $(1 \mathrm{nF})$. Any possible significant frequency shift caused by parasitic capacitances can be easily compensated by the adjustment of the values of transconductances (in case of the implementation of the OTA elements with the ability of the electronic control of its transconductance, combination of LT1228 and the UCC as mentioned before, for example) as long as the ration between the transconductances remains unchanged. The effect of real part of input and output impedances (that they are not high or low enough in comparison to the ideal impedances which are infinite or zero based on specific input/output) will affect the level of the band-stop area of available transfer functions. This can be most noticeable in case of the $3^{\text {rd }}$-order HP function in Fig. 4. This can be partly compensated by the suitable selection of used active elements with their input/output impedances closer to the ideal characteristics.

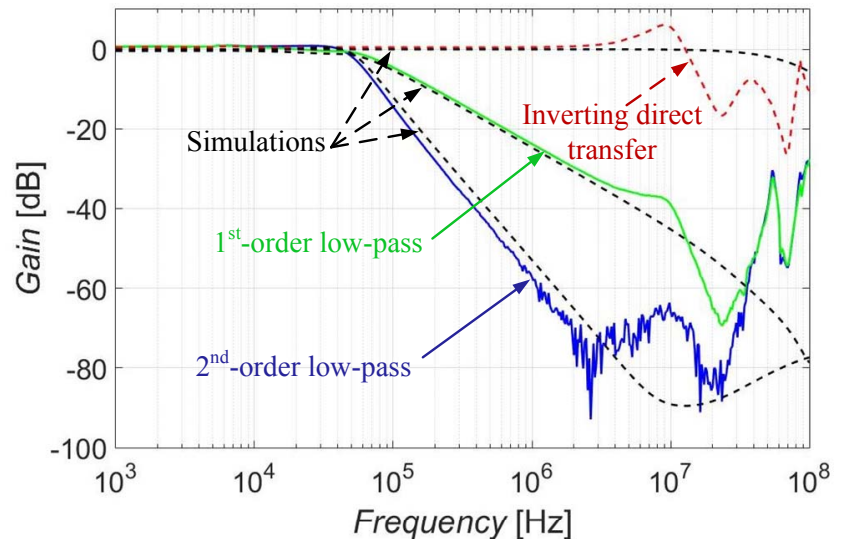

a)

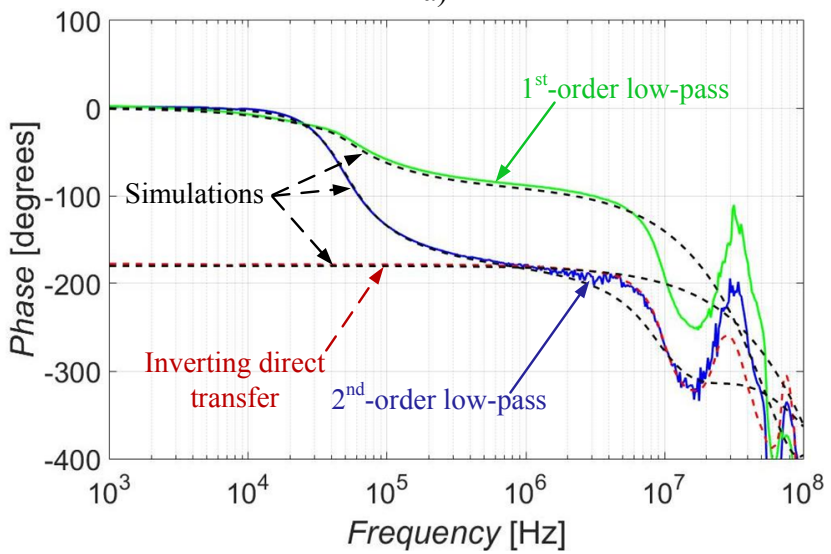

b)

Fig. 5. Transfer functions IDT, $2^{\text {nd }}$-order LP and $1^{\text {st }}$-order LP: a) magnitude characteristics, b) phase characteristics.

The pole frequency of the filter can be easily controlled by changing the values of the transconductances $g_{\mathrm{m} 1}, g_{\mathrm{m} 2}$ and $g_{\mathrm{m} 3}$ as long as the ratio between them is kept unchanged. This ability is demonstrated by the $3^{\text {rd }}$-order LP function in Fig. 6 for three different settings $\left(g_{\mathrm{m} 1}=75 \mu \mathrm{S}\right.$, $g_{\mathrm{m} 2}=150 \mu \mathrm{S}, \quad g_{\mathrm{m} 3}=300 \mu \mathrm{S}$, the second setting is $g_{\mathrm{m} 1}=150 \mu \mathrm{S}, g_{\mathrm{m} 2}=300 \mu \mathrm{S}, g_{\mathrm{m} 3}=600 \mu \mathrm{S}$ and the third one is $g_{\mathrm{m} 1}=300 \mu \mathrm{S}, g_{\mathrm{m} 2}=600 \mu \mathrm{S}, g_{\mathrm{m} 3}=1200 \mu \mathrm{S}$ resulting in the theoretical pole frequency of $23.8 \mathrm{kHz}, 47.4 \mathrm{kHz}$ and $94.6 \mathrm{kHz}$ ). Obtained simulated and measured frequencies are compared in Tab IV. All tested frequencies are close to the theoretical expectations.
TABLE IV. SUMMARY OF THEORETICAL, SIMULATED AND MEASURED POLE FREQUENCIES

\begin{tabular}{|c|c|c|c|}
\hline Theoretical $f_{0}[\mathrm{kHz}]$ & 23.8 & 47.4 & 94.6 \\
\hline Simulated $f_{0}[\mathrm{kHz}]$ & 20.7 & 45.3 & 93.8 \\
\hline Measured $f_{0}[\mathrm{kHz}]$ & 23.4 & 46.1 & 95.9 \\
\hline
\end{tabular}

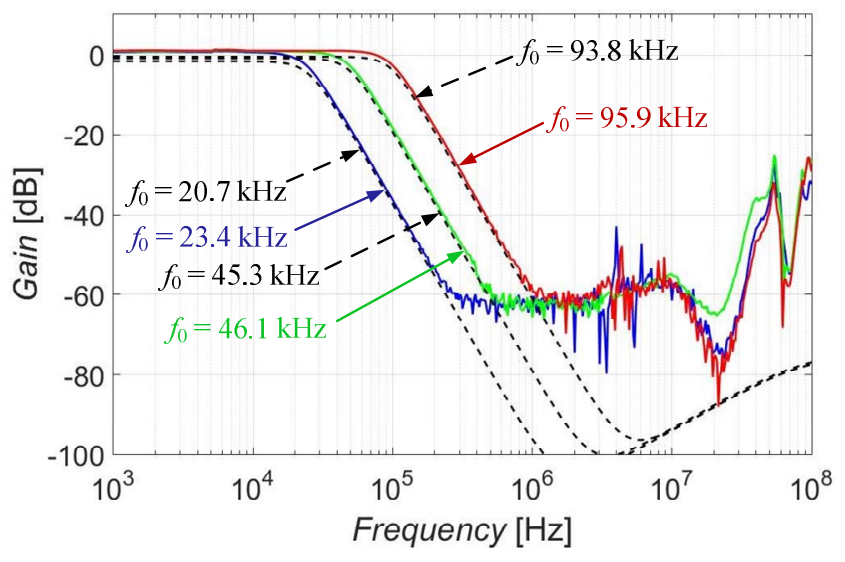

Fig. 6. Possibility of $f_{0}$ control in case of the $3^{\text {rd }}$-order LP function for three different configurations of the transconductances.

\section{CONCLUSION}

The simulation results and more importantly experimental results support the design of the proposed $3^{\text {rd }}$ order reconnection-less electronically reconfigurable filter. All supposed transfer functions are available depending on the setting of current gains $B_{0}$ to $B_{3}$. The proposed filter offers thirteen functions in total. The control of the pole frequency is operating as intended and closely follows the theoretical presumptions. The future work should consist of the further analysis of the filter in order to possibly obtain even more transfer functions from given structure.

\section{REFERENCES}

[1] R. Sotner, L. Langhammer, O. Domansky, J. Petrzela, J. Jerabek, T. Dostal, "New reconfigurable universal SISO biquad filter implemented by advanced CMOS active elements," In Proc. 15th IEEE Int. Conf. Synthesis, Modeling, Analysis and Simulation Methods and Applications to Circuit Design (SMACD 2018), Prague, Czech Republic, 2018, pp. 257-260.

[2] R. Sotner, J. Petrzela, J. Jerabek, K. Vrba, T. Dostal, "Solutions of reconnection-less OTA-based biquads with electronical transfer response reconfiguration," In Proc. 25th Int. Conf. Radioelektronika, Pardubice, Czech Republic, 2015. pp. 40-45.

[3] L. Langhammer, R. Sotner, J. Dvorak, J. Jerabek, P. A. Ushakov, "Novel Reconnection Reconnection-Less Reconfigurable Filter Design Based on Unknown Nodal Voltages Method and Its Fractional Fractional-Order Counterpart," Elektronika ir Elektrotechnika, vol. 25, no. 3, 2019, pp. 34-38.

[4] J. Jerabek, R. Sotner, J. Polak, K. Vrba, T. Dostal, "Reconnectionless electronically reconfigurable filter with adjustable gain using voltage differencing current conveyor," Elektronika ir Elektrotechnika, vol. 22, no. 6, 2016, pp. 39-45.

[5] L. Langhammer, R. Sotner, J. Dvorak, T. Dostal, "Novel Design Solution of Reconnection-less Electronically Reconfigurable Filter," In Proc. of the 26th International Conference Mixed Design of Integrated Circuits and Systems - MIXDES 2019. Rzesow, Poland, 2019. pp. 365-369.

[6] R. Sotner, J. Petrzela, J. Jerabek, T. Dostal, "Reconnection-less OTA based biquad filter with electronically reconfigurable transfers," Elektronika ir Elektrotechnika, vol. 21, no. 3, 2015, pp. 33-37. 
[7] A. K. Singh, P. Kumar, R. Senani, "Fully-differential current-mode higher order filters using all grounded passive elements," Int. J. Electron. Commun. (AEÜ), vol. 97, 2018, pp. 102-109.

[8] P. Brandstetter, L. Klein, "Third Order Low-Pass Filter Using Synthetic Immittance Elements with Current Conveyors," Theoretical and Applied Electrical Engineering, vol. 10, no. 2, 2012, pp. 89-94.

[9] A. Ranjan, S. K. Paul, "Realization of Active-C Voltage Mode Third Order Band Pass Filter with Current Controlled Current Conveyor (CCCII)," In Proc. International Conference on Electronic Devices, Systems and Applications (ICEDSA 2011), Kuala Lumpur, Malaysia, 2011, pp. 229-231.

[10] M. Kumngern, K. Klangthan, "0.5-V Fourth-Order Low-Pass Filter," In Proc. 2nd International Conference on Automation, Cognitive Science, Optics, Micro Electro-Mechanical System, and Information Technology (ICACOMIT), Jakarta, Indonesia, 2017, pp. 119-122.

[11] S. Minaei, E. Yuce, "High-Order Current-Mode Low-Pass, High-Pass and Band-Pass Filter Responses Employing CCCIIs," In Proc. 6th International Conference on Information, Communications \& Signal Processing, Singapore, Singapore, 2007, pp. 1-4.

[12] H. Tarunkumar, A. Ranjan, N. M. Pheiroijam, "Fourth Order Band Pass and All Pass Filter using Single FTFN," In Proc. International Conference on Computer Communication and Informatics (ICCCI 2018), Coimbatore, India, 2018, pp. 1-3.

[13] A. Ranjan, S. K. Paul, "Nth Order Voltage Mode Active-C Filter Employing Current Controlled Current Conveyor," Circuits and Systems, vol. 2, no. 2, 2011, pp. 85-90.

[14] T. Dostal, "Filters with multi-loop feedback structure in current mode," Radioengineering, vol. 12, no. 3, 2003, pp. 6-11.

[15] D. Biolek, Z. Kolka, B. Sviezeny, "Teaching of electrical circuits using symbolic and semisymbolic programs," In Proc. of the 11th Conference EAEEIE, Ulm, Germany, 2000, pp. 26-30.

[16] D. Biolek, R. Senani, V. Biolkova, Z. Kolka, "Active elements for analog signal processing: Classification, review, and new proposals," Radioengineering, vol. 17, no. 4, 2008, pp. 15-32.
[17] R. Sponar, K. Vrba, "Measurements and Behavioral Modelling of Modern Conveyors," International Journal of Computer Science and Network Security, vol. 3A, no. 6, 2006, pp. 57-63.

[18] Linear Technology, LT1228 Current Feedback Amplifier with DC Gain Control (datasheet), accessible on http://cds.linear.com/docs/en/datasheet/1228fd.pdf.

[19] L. Langhammer, R. Sotner, J. Dvorak, "Modification of Current Follower/Amplifier with Controllable Intrinsic Resistance," In Proc. of IEEE 2018 41st International Conference on Telecommunications and Signal Processing (TSP2018), Athens, Greece, 2018. pp. 70-73.

[20] Intersil (Elantec), EL2082 CN Current-mode multiplier (datasheet), 1996 , accessible on http://pdf.datasheetcatalog.com/datasheet/elantec/EL2082CN.pdf.

[21] K. Hajek, J. Sedlacek, "NAFID program as powerful tool in filter education area," In Proc. of the Conference CIBLIS'97, Leicester, United Kingdom, 1997, pp. PK-4 1-10.

[22] J. Jerabek, R. Sotner, K. Vrba, "Electronically Adjustable TripleInput Single-Output Filter with Voltage Differencing Transconductance Amplifier," Revue Roumaine des Sciences Techniques - Serie Électrotechnique et Énergétique, vol. 59, 2015, pp. 163-172.

[23] J. Jerabek, R. Sotner, K. Vrba, "General Current-Mode Filtering Structure with Controllable Current Active Elements," In Proc. 36th international conference on telecommunications and signal processing (TSP 2013), Rome, Italy, 2013, pp. 402-406.

[24] R. Sotner, N. Herencsar, J. Jerabek, R. Prokop, A. Kartci, T. Dostal, K. Vrba, "Z-Copy Controlled-Gain Voltage Differencing Current Conveyor: Advanced Possibilities in Direct Electronic Control of First-Order Filter," Elektronika ir elektrotechnika, vol. 20, 2014, pp. 77-83.

[25] Texas Instruments - OPA860 - Wide Bandwidth Operational Transconductance Amplifier (datasheet). accessible on http://www.ti.com/lit/ds/symlink/opa860.pdf.

[26] Texas Instruments - OPA861 - Wide Bandwidth Operational Transconductance Amplifier (datasheet). accessible on http://www.ti.com/lit/ds/symlink/opa861.pdf. 